\title{
Modification of the electrically elicited eyeblink by acoustic, visual, and vibrotactile pulses
}

\author{
ANITA J. SARNO and TERRY D. BLUMENTHAL \\ Wake Forest University, Winston-Salem, North Carolina \\ and \\ A. J. W. BOELHOUWER \\ Tilburg University, Tilburg, The Netherlands
}

\begin{abstract}
The purpose of the present research was to investigate the cross-modal integration of sensory information in the blink reflex circuit. In three experiments, the eyeblink reflex was elicited by an electrical pulse to the forehead in college students. Weak pulses were acoustic in Experiment $1(N=28)$, visual in Experiment $2(N=17)$, and vibrotactile in Experiment $3(N=17)$. The R2 component of the electrically elicited eyeblink reflex was facilitated by weak acoustic pulses that were presented at the same time as or shortly after the electrical stimulus. A weak visual pulse also facilitated the blink reflex, but only when visual pulse onset preceded or occurred simultaneously with the electrical stimulus. Vibrotactile pulses presented to the hand did not cause facilitation at any interval. Weak pulses in all three sensory modalities presented before the blink-eliciting stimulus were able to inhibit the eyeblink reflex. These results suggest that the temporal summation that leads to facilitation of the blink response by weak stimuli occurs at a common location at which electrical, acoustic, and visual, but not vibrotactile, information converges. These data also show that facilitation and inhibition of the blink response are based on different underlying mechanisms.
\end{abstract}

The purpose of the present series of experiments was to use the electrically elicited blink reflex in humans to investigate convergence of sensory input. Convergence of activation in different sensory systems was evaluated by measuring temporal summation of stimulus-driven response elicitation. This study compared the impact of weak stimuli in three different sensory modalities on the electrically elicited blink reflex. Given the depth of knowledge concerning the neural pathways underlying the elicitation of the blink reflex, the results of these studies may help to identify the neural mechanisms underlying blink reflex modification.

The eyeblink reflex has been shown to be a valuable probe in the fields of psychology and neuroscience due to its plasticity (Hackley \& Johnson, 1996). Eyeblink reflexes can be elicited with electrical stimuli (Brunia \& Boelhouwer, 1988; Shahani \& Young, 1973), acoustic stimuli (Blumenthal \& Goode, 1991; Graham, 1975), cu-

Portions of this research were supported by a RECREAC grant from Wake Forest University and by the dean of the graduate school at Wake Forest University. Data from Experiment 1 were presented at the Society for Psychophysiological Research meeting in Toronto, October 1995; data from Experiment 2 were presented at the Southeastern Psychological Association meeting in Norfolk, VA, March 1996; and data from Experiment 3 were presented at the Society for Psychophysiological Research meeting in Vancouver, October 1996. Experiments I and 3 were completed as part of the degree requirements of A.J.S. in the psychology master's program at Wake Forest University. We would like to thank Siobhan Andrews, Matt Schmolesky, Ed Schicatano, and Kevin Muse for their assistance. Correspondence should be addressed to T. D. Blumenthal, Department of Psychology, Wake Forest University, Winston-Salem, NC 27109 (e-mail: blumen@wfu.edu). taneous stimuli (Haerich, 1994; Hoffman, 1984), or visual stimuli (Hackley \& Johnson, 1996; Yates \& Brown, 1981). Electrically elicited eyeblinks involve two components, an ipsilateral R1 with a latency of 8-12 msec and a bilateral R2 with a latency of $25-40 \mathrm{msec}$ (Brunia \& Boelhouwer, 1988). Acoustically elicited eyeblinks involve a bilateral R2 response with a latency as short as $27 \mathrm{msec}$ (Takmann, Ettlin, \& Barth, 1982). Eyeblinks elicited with an airpuff or a tap to the glabella involve a single-response component with a latency of 55-60 msec (Haerich, 1994; Hoffman \& Ison, 1992). Visually elicited blinks generally involve two bilateral components, an R50 with a latency of 45-55 msec and an R80 with a latency of 75-95 msec (Hackley \& Boelhouwer, 1997).

The blink reflex can be modified by the presentation, withdrawal, or alteration of another stimulus, by intrinsic variables of the subject, or by variations in the eliciting stimulus itself (Anthony, 1985; Graham, 1975). This reflex modification has been studied for decades, in a wide range of species and conditions (Hackley \& Boelhouwer, 1997; Hoffman, in press). One type of reflex modification that has been extensively studied is lead stimulus inhibition (Graham, 1975), a phenomenon by which a weak stimulus presented before the startle-eliciting stimulus inhibits reflex eyeblink magnitude. The time interval between the onsets of the two stimuli, or stimulus onset asynchrony ( $\mathrm{SOA}$ ), is an important aspect of this paradigm. When the weak stimulus is presented before the startle stimulus, this condition is called a positive SOA (Figure 1). ' SOAs of 30-500 msec produce inhibition of blink reflex magnitude (Anthony, 1985). 
Temporal summation refers to the process of integrating stimulus energy over time, with response magnitude increasing as stimulus duration or number increases (Gelfland, 1990; Zwislocki, 1969). The time window in which this summation occurs can be identified as the point at which the response increment as a function of stimulus duration reaches asymptote. The summation window can also be identified by measuring the response increment added by the second stimulus in a pair while varying the interval between the two stimuli. After some critical interval, the combined effect of the two stimuli will be no greater than that of one stimulus presented alone, and this is the point at which the summation window is exceeded. Temporal summation is a characteristic of all sensory systems and, indeed, of neural integration at the most basic level. Evaluation of temporal summation can be used to assist in identifying the neural mechanisms underlying information processing (Zwislocki, 1969, 1983).

Blink reflex magnitude in humans increases as the duration of the blink-eliciting stimulus is increased to approximately $50 \mathrm{msec}$ (Blumenthal \& Berg, 1986). Research has also shown that increasing the number of blink-eliciting stimuli from one to two can increase startle response magnitude (Blumenthal \& Berg, 1986; Plant \& Hammond, 1989). These data show that the blink reflex can be used to demonstrate temporal summation of stimulus input at the brain stem level. Several studies have also shown that temporal summation can occur when a blinkeliciting stimulus is paired with a weak stimulus that cannot, itself, activate the blink reflex. The weak stimulus is thought of as a "modifier" of the blink reflex but, when that modification effect is facilitatory and when the time between the two stimuli is very brief, temporal summation is a likely explanation for this facilitatory effect. For example, some studies have shown that lead stimuli presented at very short positive SOAs demonstrate blink reflex facilitation (Blumenthal \& Tolomeo, 1989; Graham, 1980). A negative SOA condition exists when the startle stimulus is presented prior to the weak pulse, and this can also result in facilitation of the blink reflex (Boelhouwer, Teurlings, \& Brunia, 1991; Schmolesky, Boelhouwer, \& Blumenthal, 1996).

Boelhouwer et al. (1991) investigated the facilitatory effect of a weak acoustic pulse on the electrically elicited eyeblink response when the acoustic pulse was presented prior to, at the same time as, or after the electrical stimulus. The early R1 response component was facilitated when the weak acoustic pulse preceded the electrical stimulus by $100 \mathrm{msec}$ or less. The $\mathrm{R} 2$ response component was facilitated at SOAs of -60 to $10 \mathrm{msec}$ and inhibited at SOAs of $40 \mathrm{msec}$ and greater. Boelhouwer et al. (1991) hypothesized that the facilitatory effects were a factor of temporal summation at the facial motor nucleus, based on the time of arrival of the separate neural volleys generated by the acoustic and electrical stimuli. The neural signals generated by both stimuli contribute to the activation of the response. At longer positive SOAs, the neural activation caused by the electrical stimulus arrives at the facial motor nucleus after the neural signal generated by the weak acoustic pulse has dissipated, resulting in no temporal summation and no impact on the blink reflex. Schmolesky et al. (1996) reported a similar facilitation of the electrically elicited eyeblink response by weak acoustic pulses. In addition, Schmolesky et al. found that increasing the intensity of the weak acoustic pulse resulted in greater facilitation of the blink reflex. This is further evidence in support of the convergence of neural events activated by the acoustic and electrical stimuli at some point in the blink reflex arc.

Rimpel, Geyer, and Hopf (1982) investigated the effects of input from different sensory systems on the startle eyeblink response and found that blink response habituation
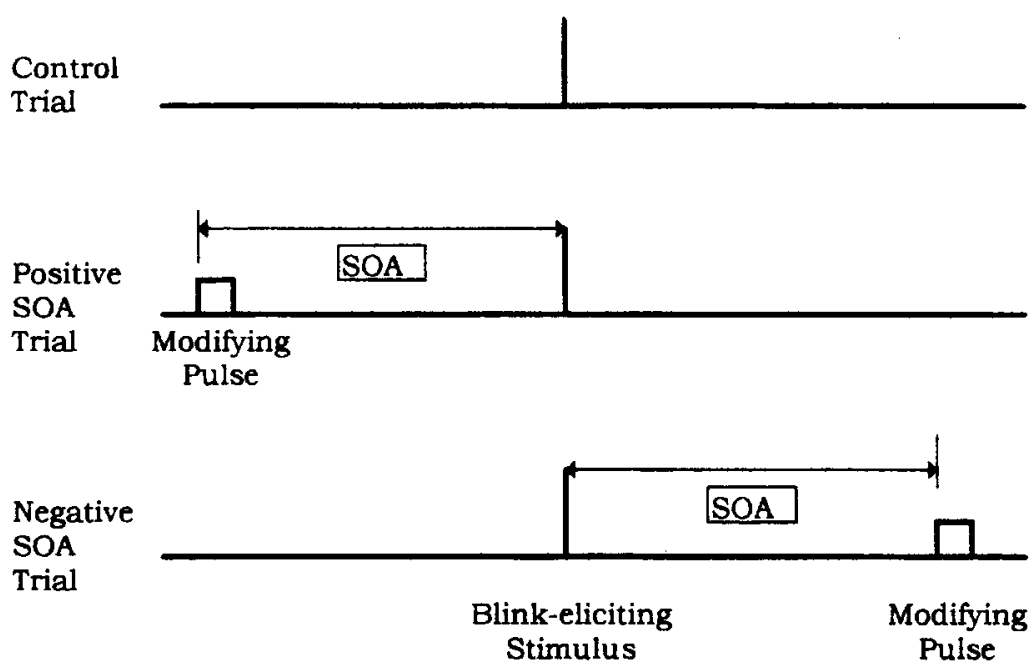

Figure 1. Experimental conditions representing the relationship between a blinkeliciting stimulus and a weak pulse. A positive stimulus onset asynchrony (SOA) involves the weak pulse's being presented first, and a negative SOA involves the electrical stimulus's being presented first. 
transferred across modalities. Rimpel et al. stated that the transfer of habituation was based on the involvement of interneurons that are shared by the reflex arcs activated by stimuli in visual, auditory, and cutaneous (electrical) modalities. Therefore, if the reflex arcs responsible for blinks elicited by stimuli in several modalities share interneurons, temporal summation may be expected when stimuli in the same or different modalities are presented close together in time. If the blink-eliciting stimulus and weak acoustic pulse are both reflexogenic, the interneurons discussed by Rimple et al. may be located in the nucleus reticularis pontis caudalis (nRPC), the startle center identified by Lee, Lopez, Meloni, and Davis (1996), or some other common location in the reflex arc (Yeomans \& Frankland, 1996). One such location is the facial motor nucleus, which is responsible for activating the muscle (orbicularis oculi) from which the blink reflex is recorded.

Rimpel et al. (1982) and Boelhouwer et al. (1991) have shown that temporal summation is not determined by the timing of stimulus presentation, but by the timing of the arrival of neural activation at a common location. If two stimuli in different modalities are presented simultaneously, the transmission of the neural signal may be faster in one modality than in the other, due to either differences in conduction velocity or to length or complexity (number of synapses) of the pathway. In this case, neural activation generated by a stimulus that follows the blinkeliciting stimulus can facilitate the blink reflex through temporal summation of neural excitation at a common location. Here, blink reflex facilitation can be used to demonstrate convergence of sensory stimulation. This is the mechanism that may underlie facilitation of blink reflex magnitude by weak acoustic pulses that are presented at a negative SOA. Therefore, blink facilitation by weak pulses at negative SOAs can be used to investigate convergence of reflex arcs, as well as transmission time (determined by either conduction velocity or pathway complexity) in these reflex arcs. If the two pathways converge but transmission time is not shorter in the "weak pulse" pathway, we expect facilitation at positive or simultaneous SOAs, but not at negative SOAs. Facilitation at negative SOAs shows that transmission is faster in the pathway subserving the "weak pulse" than in that subserving the electrical stimulus. If the pathways do not converge, no facilitation should be seen.

In the present series of studies, blinks were elicited with an electrical pulse to the forehead (trigeminal) in adult humans. Weak pulses were presented in three different modalities: acoustic, visual, and vibrotactile in Experiments 1,2 , and 3 , respectively. ${ }^{2}$ The extent to which the reflex arcs of each modality converge with that of the electrical blink can be demonstrated by the presence of facilitation of the blink reflex. The relative transmission time in each pathway can be estimated by the SOAs at which this facilitation is present. The fact that the electrically elicited blink reflex includes two components means that these convergent effects can be investigated in two distinct neural pathways (Ongerboer de Visser \& Kuypers, 1978), a short ipsilateral pontine pathway (Rl) and a longer bilateral medullary pathway (R2).

\section{EXPERIMENT 1}

In Experiment 1, weak acoustic pulses were presented, and it was expected that facilitation of blink magnitude would be observed at short negative and simultaneous SOAs. A second factor in this experiment was the inclusion of a task. Both the Boelhouwer et al. (1991) and the Schmolesky et al. (1996) studies had subjects perform a task. The Boelhouwer et al. study asked the subjects to blink their right eye in response to the weak acoustic pulse. In the Schmolesky et al. study, subjects were required to count control trials (trials on which they experienced the electric stimulus alone, not in conjunction with a weak acoustic pulse). It could be the case that level of attention operates as a mediator in the enhancement of the eyeblink reflex, and that the complex decision task (Boelhouwer et al.) required more attention than a simple presence-or-absence decision (Schmolesky et al).

\section{Method}

Subjects. Twenty-nine subjects participated in this experiment for partial credit in an undergraduate psychology course at Wake Forest University. One subject was not included due to a medical concern. The remaining 28 subjects ( 10 females and 18 males) ranged in age from 18.0 to 20.1 years $(M=18.6)$ and reported no history of hearing loss or significant medical problems.

Stimuli and Apparatus. The electrical stimulus (0.1-msec duration) was generated by a Grass SD9 stimulator in series with a Grass CCU-1 A constant current unit and delivered through SensorMedics miniature $\mathrm{Ag} / \mathrm{AgCl}$ surface electrodes (4-mm diameter contactor, filled with conducting paste). Electrodes were placed over the foramen of the trigeminal nerve located at the arch of the left eyebrow so that the center of the cathode was directly over the supraorbital branch of the trigeminal nerve and the center of the anode was $2 \mathrm{~cm}$ above that. The electrical stimulus was calibrated individually for each subject (range $=4-12 \mathrm{~mA}$ ) so that $\mathrm{R} 1$ was maximal, yet the shock was not uncomfortable to the subject. The shock intensity remained constant throughout the session.

The acoustic stimulus ( $70 \mathrm{~dB}[\mathrm{~A}])$, broadband noise $(20 \mathrm{~Hz}-$ $20 \mathrm{kHz}$ ), 5 -msec rise/fall time, 25 - or 50 -msec duration) was generated by a Coulbourn noise generator, gated by a Coulbourn rise/ fall gate, amplified by a Coulbourn audio mixer, and delivered to the subject with Telephonics TDH-49P headphones.

Two recording electrodes (SensorMedics miniature $\mathrm{Ag} / \mathrm{AgCl}$ surface electrodes, 4-mm-diameter contactor, filled with conducting paste) were placed on the skin overlaying the orbicularis oculi muscle of the left eye, the first one positioned directly below the pupil and the second one lateral to the first, with the centers of the two electrodes 12-15 mm apart. A ground electrode was placed on the left temple. The EMG recorded from the orbicularis oculi muscle was filtered by a Coulbourn high-gain bioamplifier (passband $90-$ $250 \mathrm{~Hz}$ ) and then digitally sampled once every millisecond for $500 \mathrm{msec}$ by a Biopac MP 100 interface, beginning $150 \mathrm{msec}$ before electrical stimulus onset. These samples were stored on a Macintosh II computer.

Six SOAs (acoustic stimulus onset to electrical stimulus onset) were employed: a positive SOA condition in which acoustic pulse 
onset preceded the electrical stimulus by $120 \mathrm{msec}$; a simultaneous condition (0-msec SOA) in which both the acoustic and electrical stimuli began at the same time; and four negative SOA conditions, in which acoustic pulse onset followed the electrical stimulus by $25,50,75$, or $100 \mathrm{msec}$. Trials were presented in five blocks of 14 trials each, with each block including one trial at each of the six SOAs crossed with the two acoustic pulse durations, plus two control trials consisting of the electrical stimulus alone. Stimulus presentation, acoustic pulse duration, and SOA conditions were randomized within blocks and controlled by a Macintosh SE computer connected to a Biopac MP10 interface.

Procedure. Subjects completed informed consent and medical forms. The experimenter then cleaned the skin over which the electrodes would be placed with a cotton swab dipped in alcohol and placed the five electrodes. If the impedance of the recording electrodes was greater than $200 \mathrm{k} \Omega$, the electrodes were removed, the skin was cleaned again, and the electrodes were reattached (this occurred for only 1 subject).

Subjects were randomly assigned to one of four experimental groups differentiated by attentional task. In the first group $(N=9)$, subjects had no attentional task; they were simply asked to sit still. In the second group $(N=9)$, subjects were asked to sit still and count control trials (electrical stimulus alone) and report the number to the experimenter at the end of the session. In the third and fourth groups $(N=5$ each), subjects were asked to sit still and discriminate between the short and long duration acoustic pulses. Group 3 responded with a press of a thumbswitch to the 25 -msec-duration acoustic stimulus, and Group 4 responded in like manner but to the 50 -msec-duration acoustic stimulus. Accuracy was stressed for all task groups. The task groups were informed that if they completed their task accurately, they would receive an additional half hour of credit. The no-task group received a bonus half hour upon completion, but they were not told of an incentive prior to their participation in the study. All subjects kept their eyes open, looking forward, throughout the session. A video monitor allowed the experimenter to view the subject from the adjacent room, but the presence of the camera was not pointed out to the subject. Four practice trials (acoustic pulses only) were presented to subjects in all groups to make sure that subjects in Groups 3 and 4 were able to discriminate between the two durations of acoustic pulses. Then the electrical stimulus intensity was calibrated, to maximize the $\mathrm{R} 1$ component.

Approximately $5 \mathrm{~min}$ later, the subject was told that the experiment would begin shortly but, due to the time delay, the first few electrical stimuli might feel more intense than the last calibration stimulus. They were assured that the intensity had not been, nor would it ever be, increased during the experiment. At the end of the session, the electrodes were removed and subjects were debriefed.

Data analysis. Raw data were reduced by BMDP programs. The value of $R 1$ magnitude was calculated as the maximum peak-topeak difference in a window of 8-22 msec after electrical stimulus onset. R1 latency was identified as the latency of the first of these maxima, either positive or negative. The raw EMG was then rectified in a window of 25-90 msec after electrical stimulus onset, and $\mathrm{R} 2$ response magnitude was quantified as the area in this window. Response duration, onset latency, and probability were scored with the assistance of the AcqKnowledge software package that accompanies the Biopac MP100 interface. Response onset latency was judged to be the first point within the $25-$ to $90-\mathrm{msec}$ window at which EMG activity was greater than that in the prewindow baseline. Response duration was the time from response onset until the EMG record returned to baseline levels. If no apparent response occurred, response probability was assigned a value of zero for that trial. The measures of $R 2$ raw rectified area and $R 1$ peak-to-peak magnitude were calculated as proportions of the appropriate control conditions. The measures of $\mathrm{R} 2$ duration, $\mathrm{R} 2$ probability, and $\mathrm{R} 1$ and R2 onset latency were calculated as differences from control.

In each of the 12 acoustic pulse conditions (six SOAs crossed with two acoustic pulse durations), an average value for the entire ses- sion was calculated by averaging the five trials in each acoustic pulse condition (all analyses were collapsed across trial blocks). The 10 control trials were also averaged within each session.

Analyses of variance (ANOVAs; BMDP4V) were performed for each dependent variable, using Greenhouse-Geisser adjusted degrees of freedom. Unadjusted degrees of freedom were reported, along with epsilon values where appropriate. Pairwise comparisons (Scheffé protected $t$ tests) were also performed, comparing responding on acoustic pulse trials with responding on control trials, for each dependent measure. Two sets of analyses were conducted for each dependent variable, one including the $120-\mathrm{msec}$ condition compared with control, and the other including the $0,-25,-50,-75$, and -100 -msec conditions. Each ANOVA included the betweensubjects variable of task group and the within-subjects variable of acoustic pulse duration. The second set of analyses also included the SOA variable.

\section{Results}

The task group variable had no significant effect on any dependent variable. A subsequent set of analyses was conducted with the data from Groups 3 and 4 pooled, and task group still had no significant effect on any measure, in a main effect or in any interaction.

Response magnitude. R1 magnitude showed no significant effects, either facilitatory or inhibitory, for any condition. The raw rectified area measure of $\mathrm{R} 2$ magnitude (proportion of control) demonstrated a significant main effect of SOA $[F(4,100)=23.12, p<.001, \varepsilon=.32]$. Acoustic pulse duration was also significant $[F(1,25)=$ $7.18, p<.05]$, with greater facilitation by longer pulses, but pulse duration did not interact with SOA. Pairwise comparisons of each SOA with control showed significant facilitation at $0,-25$, and $-50 \mathrm{msec}(p<.001)$.

The comparison of $\mathrm{R} 2$ magnitude at the positive SOA of $120 \mathrm{msec}$ with control demonstrated significant inhibition $[F(1,25)=55.55, p<.001$; Figure 2$]$. Also, a significant main effect of acoustic pulse duration was found $[F(1,25)=5.22, p<.05]$, with more pronounced inhibition by the longer duration acoustic pulse.

Onset latency. Neither the R1 nor the R2 components displayed any significant effects, facilitatory or inhibitory, for the onset latency measure.

R2 duration. $\mathrm{R} 2$ response duration demonstrated a significant effect of SOA $[F(4,96)=8.81, p<.001, \varepsilon=$ $.71]$ and a significant effect of acoustic pulse duration $[F(1,24)=25.26, p<.001$; Figure 3$]$. Acoustic pulse duration did not interact with SOA. R2 response duration was greater when longer duration acoustic pulses were presented. Pairwise comparisons of each SOA condition with the control condition showed significant effects $(p<.0001)$. At negative and simultaneous SOAs, the presence of the acoustic pulse significantly increased the duration of the R2 component of the blink reflex. At a 120msec SOA, the acoustic pulse significantly decreased R2 blink duration.

R2 probability. Compared with control, probability of responding was enhanced in the 0 - and -25 -msec SOA conditions $[F(1,25)=5.26$ and 4.43 , respectively, $p<.05]$ and inhibited in the $120-\mathrm{msec}$ SOA condition $[F(1,25)=$ $71.64, p<.001]$. No main effects or interactions of pulse duration or SOA were found. 


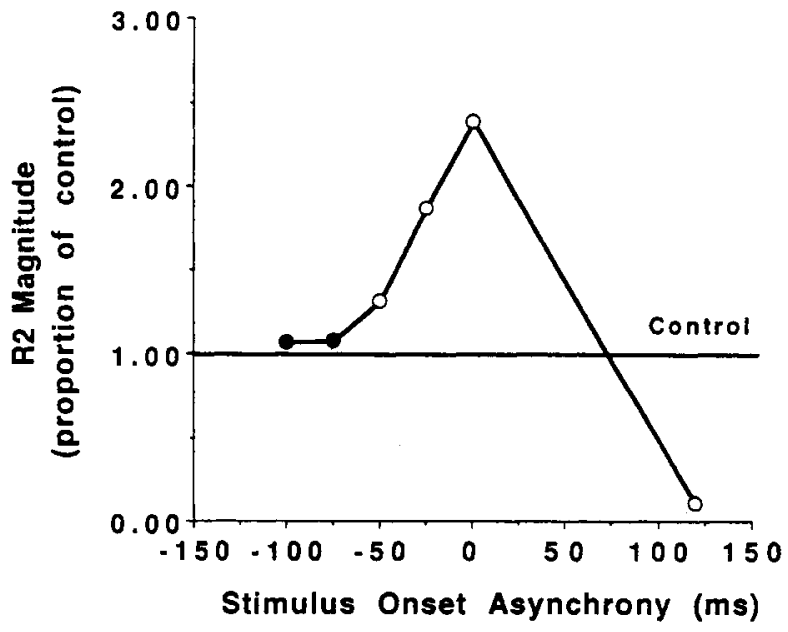

Figure 2. Experiment 1: R2 blink reflex magnitude (percentage of control condition) as a function of stimulus onset asynchrony. Zero on the abscissa represents the time of onset of the acoustic pulse. Open symbols denote significant difference from the control condition.

\section{Discussion}

The findings of the present experiment demonstrate convergence of acoustic and electrical stimulation, as shown by facilitation of the electrically elicited blink reflex by a weak acoustic pulse. Facilitation was seen at negative SOAs, suggesting that the acoustic pathway conducted information to the point of convergence, or the common location, more rapidly than did the electrical pathway. These data replicate the findings of Boelhouwer et al. (1991) and Schmolesky et al. (1996) regarding the effects of a weak acoustic pulse on the eyeblink response (inhibition at a positive SOA, facilitation at simultaneous and negative SOAs). These data also support the utility of using the startle reflex to assess sensory processing, since this reflex can show the modulating effects of stimuli that are below threshold for elicitation of the reflex. That is, weak stimuli can activate the sensory limb of the blink reflex arc at intensities below those required to activate the motor limb of that arc. ${ }^{3}$

Weak acoustic pulses at a 120 -msec positive SOA inhibited the eyeblink reflex, an effect that has been consistently demonstrated with both electrically elicited blinks (Boelhouwer et al., 1991; Schmolesky et al., 1996) and acoustically elicited blinks (Graham, 1975; Hackley \& Boelhouwer, 1997). This inhibition was more pronounced for longer acoustic pulses, similar to the results of Blumenthal (1995b) using acoustic lead stimuli and acoustic startle stimuli.

Boelhouwer et al. (1991) found that the Rl blink component showed facilitation at positive SOAs of 10 to $100 \mathrm{msec}$, peaking at a $50-\mathrm{msec}$ SOA. Schmolesky et al. (1996) found R1 facilitation at SOAs of $40-100 \mathrm{msec}$, peaking at $80 \mathrm{msec}$. In both of those studies, the R1 facilitation function was quadratic, descending as the SOA approached $100 \mathrm{msec}$. Therefore, by extrapolation to our positive SOA of $120 \mathrm{msec}$, the fact that no facilitation was found for the R1 blink component was not unexpected. Also, no effect on R1 of weak acoustic pulses at simultaneous or negative SOAs was expected, on the basis of the results of Boelhouwer et al. and Schmolesky et al. With a latency of less than $25 \mathrm{msec}$, the $\mathrm{R} 1$ response was determined before the first negative SOA acoustic pulse began in the present study.

In the Schmolesky et al. (1996) study, increasing acoustic pulse intensity augmented response magnitude facilitation, whereas in the present study, increasing acoustic pulse duration increased response magnitude facilitation and also increased response duration. These results suggest that the facilitation of blink response duration is due to the electrical and acoustic stimuli generating neural signals that are sequential, but that converge at some SOAs, resulting in temporal summation. This summation is more pronounced for longer acoustic pulses.

\section{EXPERIMENT 2}

Several researchers have reported facilitation of eyeblink reflex magnitude caused by a weak visual stimulus (Burke \& Hackley, in press, using a visual blink-eliciting stimulus with a visual pulse; Graham, 1980, using an acoustic blink-eliciting stimulus with a visual pulse; Aitken, Siddle, \& Lipp, 1995, using an acoustic blinkeliciting stimulus with a visual word stimulus). Facilitation of the electrically elicited eyeblink can also be caused by visual pulses (Boelhouwer, Frints, \& Westerkamp, 1989; Sanes, 1984). Experiment 2 was conducted to test the effects of visual pulses at three intensities on the modification of the electrically elicited eyeblink reflex.

\section{Method}

Subjects. Nineteen subjects participated in this experiment at Tilburg University, The Netherlands. One subject did not complete

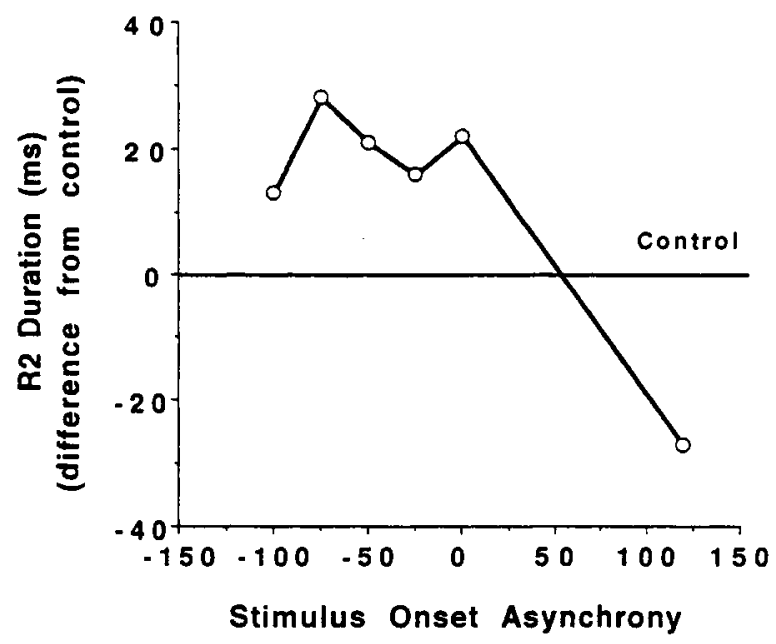

Figure 3. Experiment 1: R2 blink reflex duration (difference from control condition) as a function of stimulus onset asynchrony. Zero on the abscissa represents the time of onset of the acoustic pulse. Open symbols denote significant difference from the control condition. 
the experiment, due to electrode malfunction, and 1 subject reported that the electrical stimulation was too uncomfortable to complete the session. The remaining 17 subjects ( 9 females and 8 males) ranged in age from 19.1 to 28.7 years $(M=23.0)$ and reported no history of hearing loss or significant medical problems. The subjects were told that they would receive DFl. 17.50 for their participation in the experiment and an additional DFl. 5.00 if they correctly counted control trials, but in reality all subjects were paid DFl. 22.50 (the equivalent of $\$ 14.00$ U.S.) regardless of the number of control trials reported.

Stimuli and Apparatus. The electrical stimulus $(0.1-\mathrm{msec}$ duration) was produced by a Devices Isolated Stimulator (Type 2533) coupled in series with a Grass CCU-1A constant current unit. The electrical stimulus was delivered and calibrated in the same way as in Experiment 1. The shock intensity range was 4-12 $\mathrm{mA}$, with a mean of $8.5 \mathrm{~mA}$. The visual stimuli were produced by an incandescent light bulb placed in a box covered by two layers of white glass $(8 \times 12 \mathrm{~cm})$ to control for wavelength differences at the different light intensities. The visual stimuli were of three different intensities: $113.8,433$, and $2,030 \mathrm{~cd} / \mathrm{m}^{2}$. The intensities were calibrated by a Spectra Pritchard Photometer (Type 1980A) with a Mureen Photic VI Filter that mimics the human eye, coupled with a PM $2528 \mathrm{Au}-$ tomatic RMS multimeter. ${ }^{4}$ The light bulb filament used dictated that, as stimulus intensity was decreased, stimulus rise time increased, so that the rise time of the high-, medium-, and low-intensity visual pulses was 20,40 , and $60 \mathrm{msec}$, respectively. This means that visual pulse intensity and rise time varied together, making it impossible to determine whether any effects were due to intensity changes or to rise time changes. However, for the sake of simplicity, this variable will be referred to as "visual pulse intensity" in the Results section. Each light pulse had a duration of $70 \mathrm{msec}$, measured from the beginning of the rise time. Visual pulse fall time and duration were constant across intensity conditions. The light pulses generated no auditory component. The visual stimulus box was approximately $50 \mathrm{~cm}$ in front of the subject and approximately level with the eyes.

Stimulus presentation was controlled by an Olivetti DSM 27-140 LE computer. The EMG activity recorded by Beckman surface electrodes from the orbicularis oculi muscle was amplified (passband $4500 \mathrm{~Hz}$ ), digitized on line (A/D converters type DAS-1602, 12 bits, sample frequency $2048 \mathrm{~Hz}$ ), and stored on disk by the Olivetti computer.

Procedure. The subjects completed an informed consent form and a medical questionnaire while seated in a dimly lit, electrically shielded, sound-attenuated chamber. The time to fill out the paperwork allowed the subjects' eyes to adapt to the dim light. Electrode preparation and placement were identical to that of Experiment 1 . The subjects were asked to rest their arms on a table placed between themselves and the light stimulus. The subjects were informed that they would be experiencing the electrical stimulus on each trial, with occasional light pulses from the box in front of them. Their task was to count the control trials-trials on which an electrical stimulus was felt but the light did not occur. There were always 15 such trials per session. The purpose of the task was to keep the subjects from diverting their eyes from the light stimulus. Several light pulses of each intensity were presented prior to the beginning of the experimental session to allow the subjects to familiarize themselves with the visual stimuli. The electrical stimulus intensity was then adjusted individually to maximize R1 magnitude in each subject.

The session included 165 trials of electrical stimuli, presented in five blocks of 33 trials each. Each block consisted of randomly presented trials of each light intensity at each of the 10 SOAs $(-80$, $-60,-40,-20,0,20,40,60,80,100)$, plus three control trials. Intertrial intervals were $15-25 \sec (M=20 \mathrm{sec})$. Upon completion, the number of control trials counted by the subject was recorded, the subject was debriefed, and the electrodes were removed.
Dependent variables and analyses were similar to those in Experiment 1 , except that, due to differences in the equipment used, response probability, latency, and duration were not measured.

\section{Results}

The two-way ANOVA conducted on the peak-to-peak magnitude measure of $R 1$ revealed a significant main effect for both visual pulse intensity $[F(2,36)=34.27, p<$ $.001, \varepsilon=.71]$ and $\operatorname{SOA}[F(9,162)=29.55, p<.001, \varepsilon=$ .22]. The interaction between these two variables was also significant $[F(18,324)=18.34, p<.001, \varepsilon=.18$; Figure 4]. Follow up $t$ tests demonstrated that $\mathrm{R} 1$ magnitude was facilitated at $60-, 80-$, and 100 -msec SOAs by the high-intensity visual pulse, and at $80-$ and $100-\mathrm{msec}$ SOAs by the medium-intensity visual pulse $(p<.01)$. Facilitation by the low-intensity visual pulse never reached significance.

The two-way ANOVA conducted on the R2 response data (area of the raw rectified EMG) demonstrated significant main effects for visual pulse intensity $[F(2,38)=$ $11.62 ; \varepsilon=.93]$ and $\operatorname{SOA}[F(9,171)=13.65, p<.001$, $\varepsilon=.57]$, as well as a significant interaction between these variables $[F(18,342)=19.50, p<.001, \varepsilon=.25$; Figure 5]. Pairwise comparisons of each SOA condition with the control condition exhibited significant facilitation at 0 - and 20 -msec SOAs in the high-intensity visual pulse condition, peaking at the $20-\mathrm{msec}$ SOA. Significant facilitation in the medium-intensity visual pulse condition was demonstrated at 40- and 60-msec SOAs, peaking at the $40-\mathrm{msec}$ SOA. Facilitation in the low-intensity visual pulse condition occurred at 80 - and 100-msec SOAs, peaking at the 100 -msec SOA $(p<.05)$.

Significant inhibition of R2 occurred in the highintensity visual pulse condition at 60-, 80-, and 100-msec SOAs and in the medium-intensity visual pulse condi-

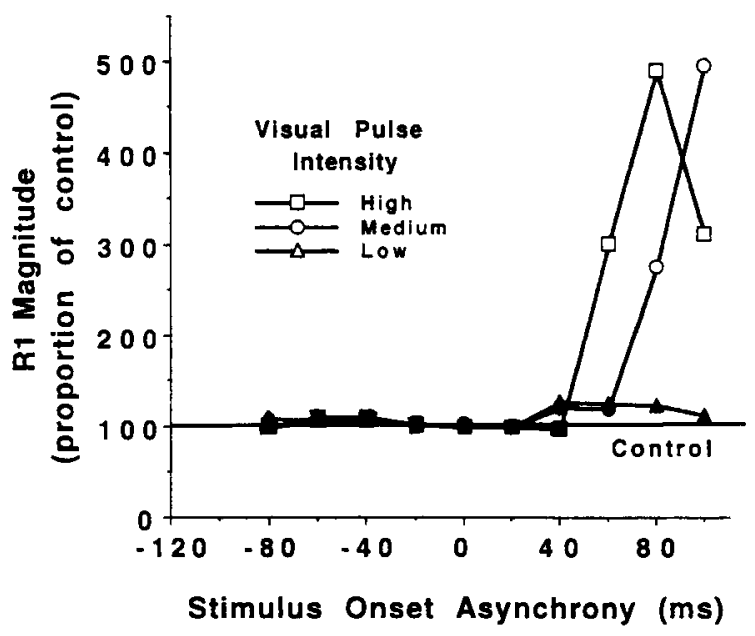

Figure 4. Experiment 2: R1 blink reflex magnitude (percentage of control condition) as a function of stimulus onset asynchrony. Zero on the abscissa represents the time of presentation of the visual pulse. Open symbols denote significant difference from the control condition. 


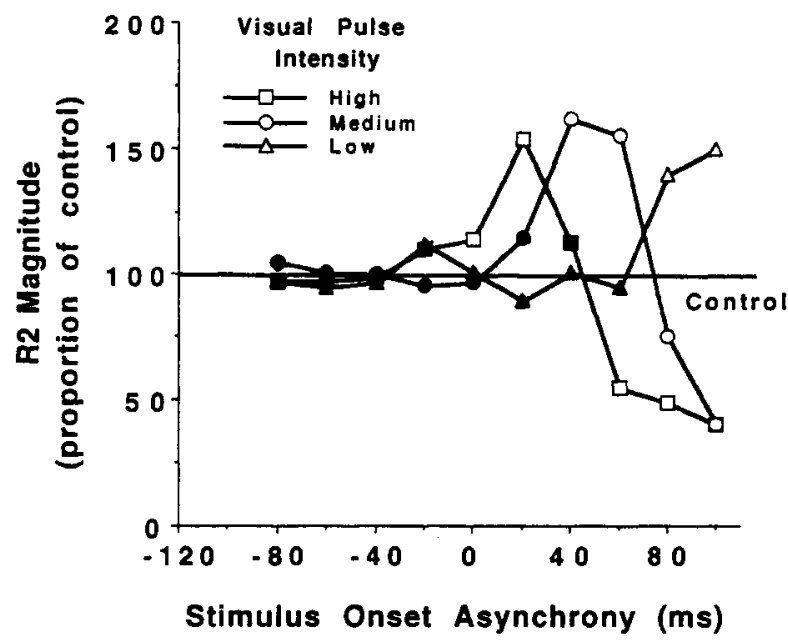

Figure 5. Experiment 2: R2 blink reflex magnitude (percentage of control condition) as a function of stimulus onset asynchrony. Zero on the abscissa represents the time of presentation of the visual pulse. Open symbols denote significant difference from the control condition.

tion at 80 - and $100-\mathrm{msec} \operatorname{SOAs}(p<.05)$. No inhibition of $\mathrm{R} 2$ was found in the low intensity visual pulse condition.

\section{Discussion}

Both the early R1 and the later R2 eyeblink response components were facilitated by a visual pulse. However, the facilitation curves of the two components followed different time courses (SOA). The inhibition of $\mathrm{R} 2$ at longer positive SOAs supports earlier demonstrations of inhibition of the blink reflex (Boelhouwer et al., 1989; Graham, 1980).

The effect of the visual pulse varied as pulse intensity and rise time varied, in that the SOAs at which facilitation of the electrically elicited blink was seen decreased as pulse intensity increased and pulse rise time decreased. Given the fact that two stimulus parameters, pulse intensity and rise time, varied together, it is not possible to determine which of these was responsible for this time shift of facilitation. However, if pulse intensity was the important factor, this effect can be discussed with reference to the results of Schmolesky et al. (1996). They found that electrical blink facilitation increased as acoustic pulse intensity increased, with no change in the SOA at which maximum facilitation occurred. This suggests that the auditory system conducted the acoustic pulse information to the temporal summation site at the same rate for all three pulse intensities. However, the present data show that the SOAs at which a visual pulse facilitated the blink reflex varied with the intensity of the visual pulse, although the maximum amount of facilitation was not affected by SOA. The visual system may have transmitted the neural stimulation produced at the three visual stimulus intensities at different rates. As visual stimulus intensity increased, the transmission time to the common location decreased, allowing for convergence with the electrically induced stimulation at shorter SOAs. This effect of visual stimulus intensity on transmission time is not unprecedented either in the blink reflex literature or in perceptual research. Yates and Brown (1981) have reported that more intense visual blink-eliciting stimuli demonstrate shorter response latencies than less intense visual blink-eliciting stimuli. Records (1979) suggested that perceptual lag, which refers to lower luminance visual stimuli demonstrating longer perception latencies than more intense visual stimuli, occurs at the ganglion cell level. The impact of visual pulse intensity on the timing of eyeblink facilitation supports the conclusion that this perceptual lag is a subcortical process.

Alternatively, the time shift of facilitation may have been due to the differences in visual pulse rise time, since the time at which facilitation occurred approached zero as visual pulse rise time decreased. This rise time difference means that the visual pulses reached their peak intensity $20 \mathrm{msec}$ earlier for each increase in pulse intensity. Given the facilitation time shift for each increase in intensity (Figure 5), the high- and medium-intensity visual pulses maximally facilitated the electrical blink when the electrical stimulus was presented at the same time that the visual pulses reached their maximum intensity. This suggests that the neural signal generated by the visual pulse may have arrived at the shared location sooner at faster rise times than at slower rise times. Blumenthal (1988) showed that the latency of the startle response increases as the rise time of an 80- or 85-dB eliciting stimulus increases, supporting this time shift as rise time varies. Future research may separately vary visual pulse intensity and rise time in an effort to identify the stimulus parameter responsible for this facilitation time shift.

The facilitation of the eyeblink in the low-intensity pulse condition at the same SOA $(100 \mathrm{msec})$ as the inhibition of the eyeblink in the medium- and high-intensity visual pulse conditions supports the proposal that these two mechanisms of modification are independent (Graham \& Murray, 1977). Further, the facilitatory and inhibitory mechanisms compete with each other for expression in the blink reflex, since both mechanisms are evaluated by measuring this reflex.

\section{EXPERIMENT 3}

A third experiment was designed to investigate the possible location of the temporal summation believed to underlie the facilitation of the electrically elicited blink by weak pulses. Boelhouwer et al. (1991) concluded that the summation that led to facilitation of the electrically elicited blink reflex was occurring at the facial motor nucleus, but they also assumed their $70-\mathrm{dB}$ weak acoustic pulses to be nonreflexogenic. However, Blumenthal and Goode (1991) showed that a 70-dB acoustic pulse with a fast rise time can itself be an effective elicitor of the startle eyeblink reflex. The question to be asked in Experiment 3 was as follows: Will facilitation of the electrically elicited blink reflex occur in conjunction with a weak pulse known to be nonreflexogenic? That is, would facilitation be expected if the sensory pathway of the weak pulse did not 
converge on the electrical blink reflex arc? The acoustic and visual pulses used in Experiments 1 and 2 could, if their intensity were increased, reliably elicit eyeblink responses. Therefore, the neural excitation caused by these stimuli might project to the brainstem centers responsible for blink reflex elicitation (Yeomans \& Frankland, 1996) or to some shared pool of interneurons (Rimpel et al., 1982). The present Experiment 3 involved the presentation of vibrotactile pulses to the hand, which have never been shown to elicit blink responses. These vibrotactile pulses have been shown in the past to modify the acoustic startle eyeblink (Blumenthal \& Gescheider, 1987; Blumenthal \& Tolomeo, 1989; Lovelace \& Blumenthal, 1991; Norris \& Blumenthal, 1996). Vibrotactile pulses generally facilitate acoustically elicited blink amplitude at 25- and 50-msec SOAs, suggesting that there is some convergence in the neural pathways of vibrotactile stimuli to the hand and acoustic blink stimuli. A vibrotactile lead stimulus to the hand can cause blink reflex inhibition from 150 to $400 \mathrm{msec}$ (Blumenthal \& Gescheider, 1987; Blumenthal \& Tolomeo, 1989), suggesting that the neural information from the vibratory pulse passes through the lateral tegmentum, the area believed to be involved in lead stimulus inhibition of startle (Swerdlow \& Geyer, 1993). 5

In the present Experiment 3, a vibrotactile pulse was presented to the thenar eminence of the hand in conjunction with an electrical blink stimulus at SOAs of -50 to $150 \mathrm{msec}$. On the basis of facilitation found with a vibrotactile pulse and an acoustic blink stimulus in previous studies, it was hypothesized that the vibrotactile pulse would facilitate the blink response at SOAs of -25 to $50 \mathrm{msec}$ and inhibit the blink response at the 150 msec SOA.

\section{Method}

Subjects. Nineteen subjects participated in Experiment 3 for partial credit in an introductory psychology course at Wake Forest University. Only the data from subjects classified as strongly righthanded by their responses to a 15-item handedness questionnaire (Dorthe, Blumenthal, Jason, \& Lantz, 1995) were used in the analyses. The data from 1 subject were excluded due to not meeting the handedness criterion, and 1 subject did not finish the experiment because the electrical stimulus was too uncomfortable. The remaining 17 subjects ( 12 female and 5 male) ranged in age from 18.0 to 24.8 years $(M=19.8)$ and reported no medical concerns.

Stimuli and Apparatus. The electrical stimulus $(0.5-\mathrm{msec}$ duration, $9 \mathrm{~mA}$ ) was produced by an MP 100 stimulator connected to a Biopac Stim-ISO unit, which was connected in series to a constant current unit (Grass CCU-1A). The electrical blink stimulus was delivered through miniature surface electrodes, as in Experiment 1. Electrode placement was identical to that of Experiment 1.

The vibrotactile pulse $(50 \mathrm{~Hz}, 40 \mathrm{~dB}$ [re: $1 \mu \mathrm{m}$ of displacement], 50 -msec duration, 5 -msec rise/fall time) was generated by a Coulbourn precision signal generator, gated by a Coulbourn rise/fall gate, amplified by a Coulbourn audio mixer, and delivered to the subject with a Ling $203 \mathrm{~B}$ shaker (vibrator) with an attached $3-\mathrm{cm}^{2}$ circular contactor. The vibrator was positioned beneath a desk top within which a $10-\mathrm{cm}^{2}$ Plexiglas plate was centered and level with the desk surface. The contactor surface of the vibrator was installed in a 2.20 -cm-diameter hole cut into the center of the Plexiglas plate so that the surface of the contactor was flush with the Plexiglas and desk surface. The vibrator contactor was centered in the hole in the Plexiglas plate, but did not touch the Plexiglas plate at any point. The vibration intensity was assessed with an Endevco Model 2221D accelerometer attached to the post between the contactor and the vibrator, and monitored by a Fluke Model $8050 \mathrm{~A}$ voltmeter. The pulses were well above detection threshold, estimated on the basis of pilot testing with subjects whose data were not included in this study.

Stimulus presentation and timing were controlled by the experimenter with a thumbswitch that triggered a cascade of timers in series with a Coulbourn decade switch. The decade switch was connected to a Coulbourn retriggerable one-shot that controlled vibrotactile stimulus duration, by controlling the rise/fall gate, audio mixer, and vibrator. The experimenter pressed the thumbswitch every $15-25 \sec (M=20 \mathrm{sec})$, timed by a clock counter that was reset with each press of the thumbswitch. The eyeblink responses were recorded electromyographically, as in Experiment 1, except that the sampling duration was increased from 500 to $1,000 \mathrm{msec}$.

Procedure. The experimental procedure was similar to that of Experiment 1, with the following exceptions: The subjects completed the 15-item handedness questionnaire after completing the informed consent form. The subjects sat at a desk with their right arms resting comfortably on the desk top. The thenar eminence of the right hand rested on the contactor surface of the vibrator. The subjects were asked to not move their right hands throughout the experimental session.

Trials were presented in eight blocks of 10 trials each, with each block including one trial in each paired condition (vibrotactile pulses at SOAs relative to electrical stimulus onset of $-25,-50,0,25$, $50,75,100$, and $150 \mathrm{msec}$ ), one electrical-stimulus-alone trial, and one vibrotactile-pulse-alone trial, randomized within a block. The electrical-stimulus-alone condition was used to establish a control level of reflex responding, and the blink response in each of the SOA conditions was compared with this control measure for indications of facilitation and inhibition. The vibrotactile-pulse-alone condition assessed the possibility that the vibrotactile pulse was itself capable of eliciting EMG activity in the orbicularis oculi muscle.

Data analysis. The same dependent variables were assessed as those in Experiment 1. The data were scored as in Experiment 1, and BMDP programs were again utilized to analyze the results, as in Experiment 1. The ANOVA included no between-subjects variable, and the within-subject variable was SOA.

\section{Results}

A sample of $100 \mathrm{msec}$ of EMG activity in the vibrationalone condition was recorded following vibrotactile pulse onset as a baseline measure to determine whether the pulse had an effect on the orbicularis oculi muscle. The average of this baseline measure was less than $0.3 \mu \mathrm{V}$, well below the magnitude of blink responses. This suggests that the vibratory pulse did not cause any EMG activity in the orbicularis oculi muscle and that there was no stimulus artifact associated with the vibrotactile pulse.

Response magnitude. The peak-to-peak measure of R1 magnitude (proportion of control) demonstrated a significant main effect of SOA $[F(7,112)=5.16, p<$ $.05, \varepsilon=.17]$. Pairwise comparisons demonstrated significant facilitation of R1 magnitude at 75- and 100msec SOAs $(p<.01$; Figure 6$)$.

The raw rectified area measure of R2 EMG magnitude (proportion of control) demonstrated a significant main effect of SOA $[F(7,112)=71.50, p<.001, \varepsilon=.54]$. Pairwise comparisons demonstrated significant inhibition of 
$\mathrm{R} 2$ area at 75-, 100-, and 150-msec SOAs ( $p<.001$; Figure 7). $\mathrm{R} 2$ response magnitude was not facilitated by the vibrotactile pulse at any SOA.

Onset latency. An ANOVA revealed no significant effects of the vibrotactile pulse on R1 latency. R2 latency (difference from control) demonstrated a significant main effect of SOA $[F(7,112)=6.79, p<.001, \varepsilon=.32]$. Pairwise comparisons demonstrated significant inhibition of R2 latency at $100-$ and $150-\mathrm{msec}$ SOAs $(p<.05)$.

Response duration. $R 2$ response duration (difference from control) demonstrated a significant main effect of $\operatorname{SOA}[F(7,112)=21.07, p<.001, \varepsilon=.42]$. Pairwise comparisons demonstrated significant inhibition of R2 duration at 50-, 75-, 100-, and 150-msec SOAs ( $p<.01$; Figure 8).

Response probability. An analysis of the probability of R2 demonstrated a significant main effect of SOA $[F(7,112)=58.55, p<.001, \varepsilon=.70]$. Compared with the control condition, probability of responding was inhibited in the 75-, 100-, and 150-msec SOAs $(p<.05)$.

\section{Discussion}

The primary hypothesis of Experiment 3, that a vibrotactile stimulus to the hand would inhibit the electrically elicited blink reflex at some SOAs and facilitate this response at other SOAs, was only partially supported. Facilitation of R 1 peak-to-peak magnitude was found, but facilitation of R2 magnitude was not observed at any SOA. Opposite effects of R1 and R2 are common (Boelhouwer et al., 1991). However, this facilitation of R1, and the inhibition of R2 at longer SOAs, are the first published demonstrations of electrical blink modification by a vibratory stimulus presented to the hand.

Ison et al. (1986) found that a weak electrical pulse to the lip can inhibit the blink reflex to an electrical pulse to

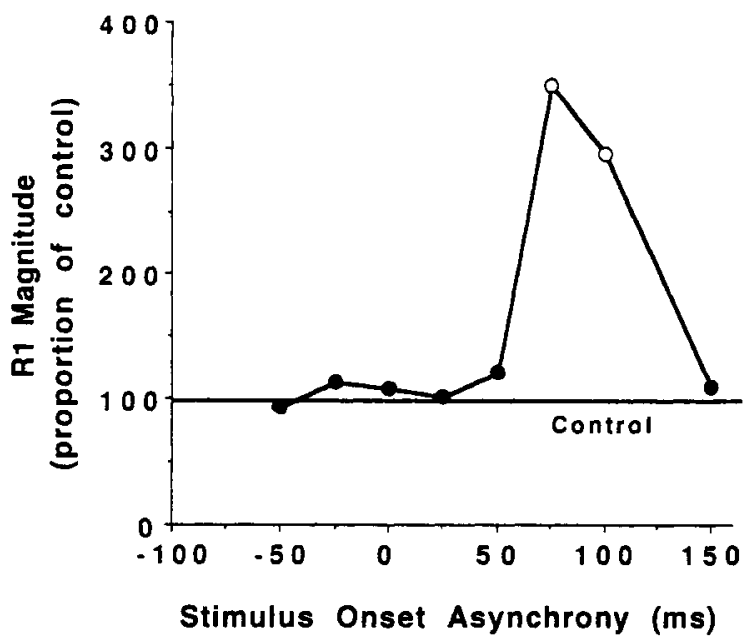

Figure 6. Experiment 3: R1 blink reflex magnitude (percentage of control condition) as a function of stimulus onset asynchrony. Zero on the abscissa represents the time of presentation of the vibrotactile pulse. Open symbols denote significant difference from the control condition.

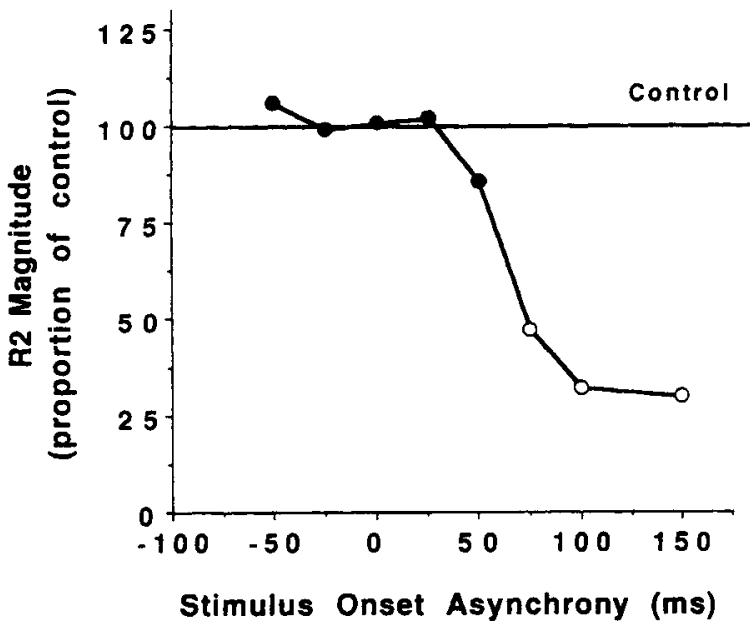

Figure 7. Experiment 3: R2 blink reflex magnitude (percentage of control condition) as a function of stimulus onset asynchrony. Zero on the abscissa represents the time of presentation of the vibrotactile pulse. Open symbols denote significant difference from the control condition.

the forehead at SOAs of $50-250 \mathrm{msec}$. Ison et al. also presented the stimulus to the lip at a 5-msec SOA, and no effect was found, but the RI blink component was facilitated at a 50-msec SOA. Similar effects were found when the weak pulse was presented to the finger rather than the lip. The data of Ison et al. suggest that electrical stimulation of the skin at a 5-msec SOA, either on the finger or the lip, does not facilitate the R2 component elicited by a subsequent electrical stimulus to the forehead, supporting the present results.

The absence of R2 facilitation in the present study was not due to the peripheral failure of processing of the weak vibrotactile pulse (e.g., the tactile pulse being below threshold), since this pulse inhibited the blink reflex at longer SOAs. This point is also demonstrated by the facilitation of the early Rl blink response component. The fact that R1 facilitation was found at 75- and 100msec SOAs suggests that if facilitation of the R2 component was to occur with a vibrotactile pulse, it would have done so at the $50-\mathrm{msec}$ SOA, due to the latency differential between the R1 and R2 components. However, the R2 component was being slightly inhibited at the 50-msec SOA, although not to the point of significance, further suggesting that a vibrotactile pulse does not facilitate the R2 component of the electrically elicited blink reflex. This conclusion is supported by the timing of facilitation reported by Blumenthal and Gescheider (1987) and Lovelace and Blumenthal (1991). Both of those studies demonstrated that the acoustically elicited blink reflex was facilitated by a vibrotactile pulse at a $50-\mathrm{msec} \mathrm{SOA}$, and both used vibrotactile pulses that were $20 \mathrm{msec}$ long and $20 \mathrm{~dB}$ above threshold. The present study used a 40-msec duration pulse with an intensity of $40 \mathrm{~dB}$, suggesting again that if facilitation were possible, it would have been readily apparent in the present study. This might suggest that the electrically elicited blink and 


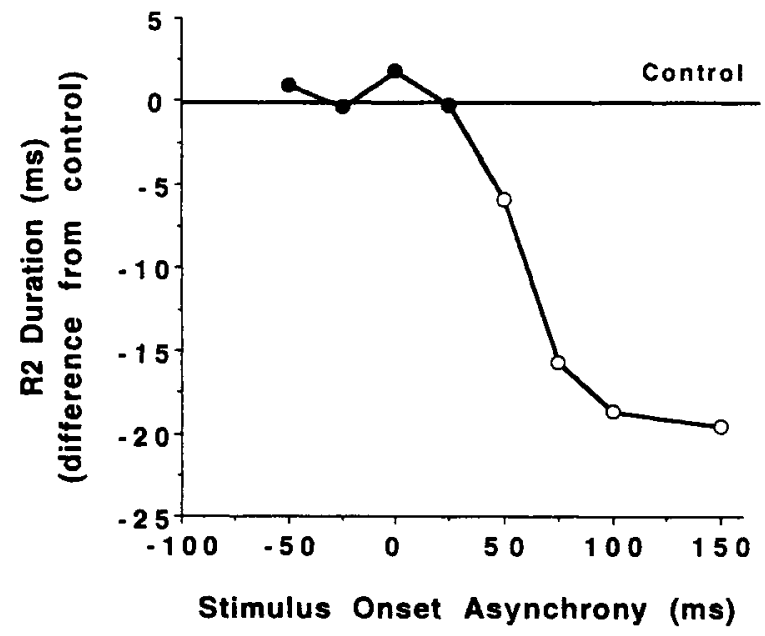

Figure 8. Experiment 3: R2 blink reflex duration (difference from control condition) as a function of stimulus onset asynchrony. Zero on the abscissa represents the time of onset of the vibrotactile pulse. Open symbols denote significant difference from the control condition.

the acoustically elicited blink are, to a certain extent, different reflexes, since a vibrotactile pulse to the hand can facilitate the acoustically elicited blink (Blumenthal \& Gescheider, 1987) but not the electrically elicited blink. These data suggest that the vibrotactile pathway converges on the acoustic blink pathway, and on the electrically activated R1 early pathway, but not on the electrically activated $R 2$ pathway.

The vibrotactile-pulse-alone condition showed that the vibrotactile pulse did not elicit reflex responding on its own. Therefore, the vibrotactile pulse does not activate the electrical blink reflex arc, and this could be an explanation for not seeing facilitatory effects of a vibrotactile pulse on the blink response. The acoustic and visual pulses used in Experiments 1 and 2 are known to elicit blinks at sufficiently high intensities. A vibrotactile pulse to the thenar eminence has never been shown to elicit a blink, although other somatosensory stimulation of sufficient intensity may elicit blinks, such as airpuffs to the temple (Haerich, 1994) and taps to the glabella (Hoffman, 1984). All previous studies observing facilitation of the electrically elicited blink used pulses that were either acoustic or visual. Also, previous studies that have found blink facilitation with vibrotactile lead stimuli have all used acoustic startle stimuli (Blumenthal \& Gescheider, 1987). Ison et al. (1986) found that electrical stimulation of the skin, either on the finger or the lip, does not facilitate a subsequent blink reflex to electrical stimulation of the forehead. The data of the present experiment support a similar conclusion for a vibrotactile pulse to the hand and suggest that the vibrotactile and electrical stimuli do not converge on or activate a common neural location, at least in terms of the later R2 blink component.

\section{GENERAL DISCUSSION}

To summarize the findings of the present studies, the R2 component of the electrically elicited eyeblink reflex was facilitated by weak acoustic pulses that were presented at the same time as or shortly after the electrical stimulus. A weak visual pulse also facilitated the blink reflex, but only when the visual pulse onset preceded or occurred simultaneously with the electrical stimulus. Also, facilitation occurred at shorter SOAs for more intense and faster rising visual pulses. Weak vibrotactile pulses presented to the hand did not cause facilitation at any SOA. Weak pulses in all three sensory modalities were able to inhibit the eyeblink reflex at positive SOAs. Although prepulse effects have been studied for decades, the impact of prepulses in three modalities, and at positive and negative SOAs, has not been previously reported in a single manuscript. The second contribution of the present paper is in showing that the facilitation seen at negative SOAs will be seen only when the modifying pulse is in a modality that can itself, at higher intensities, easily elicit a blink response. Several studies have shown blink facilitation by simultaneously presented stimuli, but the present study shows that extending SOAs into the negative time domain can help to understand those previous findings. The third contribution is the demonstration that increasing visual pulse intensity and/or decreasing visual pulse rise time shifts the time of facilitation without affecting the amount of facilitation, in contrast to Schmolesky et al. (1996), who showed that increasing acoustic pulse intensity increased the amount of the facilitation, but had no effect on the timing thereof. The fourth contribution is the demonstration of modification of electrically elicited blink responses by a vibratory stimulus to the hand, a stimulus combination that has never been published before.

Previous studies have suggested that lead stimuli presented at short positive or simultaneous SOAs can facilitate the blink response (Blumenthal \& Gescheider, 1987; Graham, 1980; Hoffman, Cohen, \& Stitt, 1981). These examples suggest that something is happening at these very short intervals. The present studies indicate that these previous results might show the end of an effect only visible with negative SOAs. The present manuscript makes a contribution beyond that of those previous studies by presenting modifying pulses at negative SOAs as well as at simultaneous and positive SOAs.

The purpose of the present research was to investigate the cross-modal integration of sensory information in the blink reflex circuit. Specifically, the three experiments reported here evaluated the conditions under which modification of the electrically elicited blink response illustrates the convergence of sensory information. The data described in this paper suggest that the facilitation of an electrically elicited eyeblink response by a weak pulse is due to the convergence at a common location of the neural 
signals generated by the two stimuli. These data can also provide information about transmission time in a neural pathway, with that transmission time being determined by speed of conduction or by length or complexity (number of synapses) of the pathway. In Experiments 1 and 2, the electrically elicited blink was facilitated by an acoustic or a visual pulse, possibly due to temporal summation of the neural input caused by the acoustic or visual stimulus and the electrical stimulus at a common location (Boelhouwer et al., 1991). The data of Experiment 1 show convergence and more rapid transmission of acoustic information than of electrical information, as shown by facilitation when the acoustic pulse was presented after the electrical stimulus. The data of Experiment 2 show convergence, but transmission in the visual pathway is slower than that in the electrical pathway, since facilitation never occurred when the visual pulse followed the electrical stimulus. Experiment 3 shows that no convergence exists for vibrotactile stimulation of the hand and the late (R2) response pathway activated by electrical stimulation of the forehead. If a stimulus is not capable of eliciting a blink reflex, even at high intensities, the neural flow generated by this stimulus might not converge on the reflex arc involved in activation of the late $\mathrm{R} 2$ component of the electrically elicited blink reflex. The vibrotactile pulses used in Experiment 3 did not elicit eyeblink responses, as shown by an absence of responding in the pulse-alone condition, and also did not facilitate blinks elicited by electrical stimuli.

The presentation of two stimuli at various SOAs is a useful paradigm for time locking and identifying the site of interacting neural events. The site for the sensory integration is hinted at by the similar or disassociative effects on $\mathrm{R} 1$ and $\mathrm{R} 2$, which are response components that involve very short neural pathways (R1) or longer neural pathways (R2; Ongerboer de Visser \& Kuypers, 1978; Trontelj \& Trontelj, 1978). Facilitation of both R1 and R2 was found in Experiment 2, suggesting that the location of the temporal summation from the neural coding of visual stimuli with both components of the electrically elicited blink reflex may occur in a place common to both circuits or, alternatively, that the two circuits behave similarly. Perhaps this common location is at a polysensory interneuron pool, as suggested by Rimpel et al. (1982), located prior to the facial motor nucleus in the blink reflex $\operatorname{arc}(\mathrm{s})$. $\mathrm{R} 1$ was facilitated in Experiment 3 using vibrotactile pulses, whereas R2 was not facilitated. This may suggest that vibrotactile stimuli impinge upon the R1 circuit where it does not overlap with the R2 circuit. The R2 component of the electrically elicited blink reflex involves projections of the spinal trigeminal nucleus to the $\mathrm{C} 1 \mathrm{re}-$ gion of the spinal cord, which then projects to unspecified interneurons, which then project to the facial motor nucleus (Pellegrini, Horn, \& Evinger, 1995). Note that the pontine startle center, nRPC (Yeomans \& Frankland, 1996), may or may not be included in this pathway. Acoustic and visual stimuli generate neural signals that activate $\mathrm{nRPC}$, with this activation leading to blink responses at sufficiently high stimulus intensities. Therefore, the site of temporal summation of the electrical stimulus effects and the acoustic or visual stimulus effects is likely to be either the nRPC or the facial motor nucleus. The neural signal generated by a vibrotactile stimulus to the hand does not pass through either of these locations, as shown by the absence of temporal summation of this neural signal with that generated by the electrical stimulus.

Depending on the SOAs used, the neural volleys from the eliciting stimulus and the weak pulse may not overlap maximally to result in facilitation compared with control. Sometimes the end of a burst of neural activity generated by one stimulus may be moving out of the summation window as the neural activity generated by the other stimulus is arriving. In this case, blink magnitude facilitation may not be seen, but response probability and response duration may be increased. To fully observe facilitative effects, it is suggested that probability and duration of the response be measured, in addition to response magnitude.

The present study was an attempt to clarify where in the blink reflex pathway the temporal summation of a weak pulse and an electrical eliciting stimulus occurs. Since weak pulses facilitate the electrically elicited blink reflex only if those weak pulses could, at higher intensities, be startle stimuli in their own right, it is likely that the temporal summation that results in this facilitation occurs at the nRPC, the brainstem startle center (Lee et al., 1996; Yeomans \& Frankland, 1996), or at the facial motor nucleus. Also, stimuli in all three modalities-auditory, visual, and vibrotactile -inhibit the eyeblink reflex. This is further support for the contention that the facilitation of the reflex eyeblink by weak pulses at very brief SOAs and the inhibition of this reflex by weak pulses at somewhat longer SOAs are based on different underlying mechanisms (Graham \& Murray, 1977).

\section{REFERENCES}

Aitken, C. J., Siddle, D. A. T., \& Lipp, O. V. (1995). The effects of threat and nonthreat word lead stimuli on blink modulation. Psychophysiology, 32, S15.

ANTHONY, B. J. (1985). In the blink of an eye: Implications of reflex modification for information processing. In P. K. Ackles, J. R. Jennings, \& M. G. H. Coles (Eds.), Advances in psychophysiology (Vol. I, pp. 167-218). Greenwich, CT: JAI Press.

Blumenthal, T. D. (1988). The startle response to acoustic stimuli near startle threshold: Effects of stimulus rise and fall time, duration, and intensity. Psychophysiology, 25, 607-611.

Blumenthal, T. D. (1995a). Comparing three methods of quantifying eyeblink magnitude. Psychophysiology, 32, S13.

Blumenthal, T. D. (1995b). Prepulse inhibition of the startle eyeblink as an indicator of temporal summation. Perception \& Psychophysics, 57, 487-494.

Blumenthal, T. D., \& BerG, W. K. (1986). The startle response as an indicator of temporal summation. Perception \& Psychophysics, 40 , 62-68.

Blumenthal, T. D., \& Gescheider, G. A. (1987). Modification of the acoustic startle reflex by a tactile prepulse: The effects of stimulus onset asynchrony and prepulse intensity. Psvchophysiologv, 24, 320-327.

Blumenthal, T. D., \& Goode, C. T. (1991). The startle eyeblink response to low intensity acoustic stimuli. Psychophysiology, 24, 296-306.

Blumenthal, T. D., \& Tolomeo, E. A. (1989). Bidirectional influ- 
ences of vibrotactile stimuli on modification of the human acoustic startle reflex. Psychobiology, 17, 315-322.

Boelhouwer, A. J. W., FrinTs, C. J. M., \& Westerkamp, V. (1989). The effect of a visual prestimulus upon the human blink reflex. Psychophysiology, 26, S14.

Boelhouwer, A. J. W., Teurlings, R. J. M. A., \& Brunia, C. H. M. (1991). The effect of an acoustic warning stimulus upon the electrically elicited blink reflex in humans. Psychophysiology, 28, 133-139.

Brunia, C. H. M., \& Boel houwer, A. J. W. (1988). Reflexes as a tool: A window in the central nervous system. In P. K. Ackles, J. R. Jennings, \& M. G. H. Coles (Eds.), Advances in psychophysiology (Vol. 3, pp. 1-67). Greenwich, CT: JAI Press.

BURKE, J., \& HACKLEY, S. A. (in press). Intramodal prepulse modulation of the early and late subcomponents of the photic eyeblink reflex. Psychophysiology.

Dorthe, N. J., Blumenthal, T. D., Jason, D. R., \& Lantz, P. E. (1995). The use of next-of-kin in assessing handedness. Perceptual \& Motor Skills, 81, 203-208.

Flaten, M. A., \& Blumenthal, T. D. (1996). The separate contributions of the tactile and acoustic components of airpuffs to the blink reflex. Psychophysiology, 33, S36.

Garner, E. E., Berg, W. K., \& Shortley, B. M. (1992). Blinks at your fingertips: Part II. The palmo-orbicularis oculi connection. Psychophysiology, 29, S33.

Gelfland, S. A. (1990). Hearing: An introduction to psychological and physiological acoustics (2nd ed.). New York: Dekker.

Graham, F. K. (1975). The more or less startling effects of weak prestimulation. Psychophysiology, 12, 238-248.

Graham, F. K. (1980). Control of reflex blink excitability. In R. F. Thompson, L. H. Hicks, \& V. B. Shvyrkov (Eds.), Neural mechanisms of goal-directed behavior and learning (pp. 511-519). New York: Academic Press.

Graham, F. K., \& Murray, G. M. (1977). Discordant effects of weak prestimulation on magnitude and latency of the reflex blink. Physiological Psychology, 5, 108-114.

HaCKLEY, S. A., \& BoElhouwer, A. J. W. (1997). The more or less startling effects of weak prestimulation-revisited: Prepulse modulation of mulicomponent blink reflexes. In P. J. Lang, R. F. Simmons, \& M. T. Balaban (Eds.), Attention and orienting: Sensory and motivational processes (pp. 205-227). Hillsdale, NJ: Erlbaum.

HACKLEY, S. A., \& JOHNSON, L. N. (1996). Distinct early and late subcomponents of the photic blink reflex: I. Response characteristics in patients with retrogeniculate lesions. Psychophysiology, 33, 239-251.

HAERICH, P. (1994). Startle reflex modification: Effects of attention vary with emotional valence. Psychological Science, 5, 407-410.

HofFMAN, H. S. (1984). Methodological factors in the behavioral analysis of startle. In R. Eaton (Ed.), Neural mechanisms of startle behavior (pp. 267-285). New York: Plenum.

HoFfman, H. S. (in press). An historical note on the "discovery" of startle modification. In M. E. Dawson, A. M. Schell, \& A. H. Boehmelt (Eds.), Startle modification: Implications for neuroscience, cognitive science, and clinical science. New York: Cambridge University Press.

Hoffman, H. S., Cohen, M. E., \& Stitt, C. L. (1981). Acoustic augmentation and inhibition of the human eyeblink. Journal of Experimental Psychology: Human Perception \& Performance, 7, 1357-1362.

HoffMan, H. S., \& ISON, J. R. (1992). Reflex modification and the analysis of sensory processing in developmental and comparative research. In B. A. Campbell, H. Hayne, \& R. Richardson (Eds.), Attention and information processing in infants and adults (pp. 83-111). Hillsdale, NJ: Erlbaum.

Ison, J. R., Foss, J. A., Falcone, P., Sakovits, L., Adelson, A. A., \& BURTON, R. I. (1986). Reflex modification: A method for assessing cutaneous dysfunction. Perception \& Psychophysics, 40, 164-170.

LEE, Y., LoPEZ, D., MELoni, E., \& DAvis, M. (1996). A primary acoustic startle pathway: Obligatory role of cochlear root neurons and the nucleus reticularis pontis caudalis. Journal of Neuroscience, 16, 3775-3789.

Lovelace, C. T., \& Blumenthal, T. D. (1991). Hand dominance and the modification of the acoustically elicited startle response by a vibrotactile prepulse. Psychobiology, 19, 265-273.

Norris, C. M., \& Blumenthal, T. D. (1996). A relationship between inhibition of the acoustic startle response and the protection of prepulse processing. Psychobiology, 24, 160-168.

Ongerboer de VisSer, B. W., \& Kuypers, H. G. J. M. (1978). Late blink reflex changes in lateral medullary lesions: An electrophysiological and neuro-anatomical study of Wallenburg's syndrome. Brain, 101, 285-294.

Pellegrini, J. J., Horn, A. K. E., \& Evinger, C. (1995). The trigeminally evoked blink reflex: I. Neuronal circuits. Experimental Brain Research, 107, 166-180.

Plant, Y., \& Hammond, G. R. (1989). Temporal integration of acoustic and cutaneous stimuli shown in the blink reflex. Perception \& Psychophysics, 45, 258-264.

RECORDS, R. E. (1979). Physiology of the human eye and visual system. New York: Harper \& Row

Rimpel, J., GEYER, D., \& HoPf, H. C. (1982). Changes in the blink responses to combined trigeminal, acoustic and visual repetitive stimulation, studied in the human subject. Electroencephalography \& Clinical Neurophysiology, 54, 552-560.

SANES, J. N. (1984). Voluntary movements and excitability of cutaneous eyeblink reflexes. Psychophysiology, 21, 653-664.

SCHMOLESKy, M. T., Boelhouwer, A. J. W., \& Blumenthal, T. D. (1996). The effect of acoustic pulse intensity upon the electrically elicited blink reflex at positive and negative stimulus onset asynchronies. Biological Psychology, 44, 69-84.

ShaHani, B. T., \& Young, R. R. (1973). Blink reflex in orbicularis oculi. In J. E. Desmedt (Ed.), New developments in electromyography and clinical neurophysiology (Vol. 3, pp. 641-648). Basel: Karger.

SWERDLOW, N. R., \& GEYER, M. A. (1993). Prepulse inhibition of acoustic startle in rats after lesions of the pedunculopontine tegmental nucleus. Behavioral Neuroscience, 107, 104-117.

Takmann, W., EtTlin, T., \& BarTh, R. (1982). Blink reflexes elicited by electrical, acoustic, and visual stimuli: I. Normal values and possible anatomical pathways. European Neurology, 21, 210-216.

Trontelj, M. A., \& TrontelJ, J. V. (1978). Reflex arc of the first component of the human blink reflex: A single motorneuron study. Journal of Neurology, Neurosurgery, \& Psychiatry, 41, 538-547.

YATES, S. K., \& BROWN, W. F. (1981). Light-stimulus-evoked blink reflex: Methods, normal values, relations to other blink reflexes and observations in multiple sclerosis. Neurology, 31, 272-281.

YeOmans, J. S., \& FrankLand, P. W. (1996). The acoustic startle reflex: Neurons and connections. Brain Research Reviews, 21, 301-314.

ZwISLOCKI, J. J. (1969). Temporal summation of loudness: An analysis. Journal of the Acoustical Society of America, 46, 320-328.

ZWISLOCKI, J. J. (1983). Group and individual relations between sensation magnitudes and their numerical estimates. Perception \& Psychophysics, 33, 460-468.

\section{NOTES}

1. A variety of terms have been used in this area of research to refer to these weak pulses. Prepulse, prestimulus, and lead stimulus all refer to any stimulus change that precedes a startle stimulus. The time between weak pulse onset and startle stimulus onset is called "lead interval," "lead time," or "stimulus onset asynchrony (SOA)." If a weak pulse follows the startle stimulus, it might be called a "postpulse," a "poststimulus," or even a "follow pulse," and the time between startle stimulus onset and postpulse onset might be referred to as "follow time" or "SOA." Rather than referring to prepulses and postpulses, we refer to these as "weak stimuli," and we use the terms positive SOA and negative SOA to refer to the time between weak pulse onset and startle stimulus onset when the weak pulse precedes or follows the startle stimulus, respectively.

2. Slight methodological differences exist among these three studies, since they were carried out in three different laboratories.

3 . Since even weak acoustic pulses can activate the blink reflex in some cases (Blumenthal \& Goode, 1991), the question becomes the following: Is the facilitation seen at negative SOAs in the present study the result of a following acoustic pulse modifying an electrically elicited eyeblink, or the result of a leading electrical stimulus modifying an acoustically elicited eyeblink? That is, which stimulus is the elicitor and which is the modifier? In the present context, we can conclude that the 
electrical stimulus is the elicitor, and the acoustic pulse is the modifier, even if the acoustic pulse can itself elicit a blink, for two reasons: (1) Although the weak acoustic pulse is a possible blink elicitor itself, it would be expected to be relatively ineffective at $70 \mathrm{~dB}$, compared with the electrical stimulus (Blumenthal, 1995a; Blumenthal \& Goode, 1991); (2) for the following acoustic stimulus to be the response elicitor, we would have to assume that the preceding electrical stimulus did not itself elicit a response on that trial. Considering the high response probability on electrical-stimulus-alone control trials $(97.50 \%)$, this absence of a blink reflex to the electrical stimulus is unlikely. Therefore, it is more sensible to think of the acoustic stimulus as a modifier of the electrically elicited eyeblink, rather than the converse.

4. These were not flashes in any sense of the word. Instead, think of a 2-D cell flashlight covered with 2, 4, or 6 sheets of white paper, for the three intensities respectively. (This is just an example, this is not how the intensities were determined. Actual intensities are found above). These visual pulses were well below threshold for elicitation of visual blinks.

5. In pilot testing, we have measured orbicularis oculi EMG while presenting intense vibratory pulses to the thenar eminence, and we have never seen any level of responding different from that seen on nostimulus baseline trials (spontaneous EMG activity). Of course, this does not guarantee that a vibration to the hand can never produce an eyeblink. These findings merely show that eliciting blinks with acoustic or visual stimuli is relatively easy, and eliciting blinks with vibrotactile stimuli is not. Also, acoustic and visual stimuli that are too weak to elicit the blink reflex can readily become blink-eliciting stimuli simply by increasing their intensity slightly. The same cannot be said of vibrotactile stimuli. Garner, Berg, and Shortley (1992) reported that the probability (but not the magnitude) of an eyeblink was enhanced when an airpuff was directed at the hand, as opposed to away from the hand. This effect was found in females, but not in males. However, airpuff stimuli often involve a brief sound as well as a tactile component, and Flaten and Blumenthal (1996) have shown that the acoustic component of an airpuff can elicit an eyeblink reflex. The eyeblinks seen by Garner et al. are more likely to have been elicited by the acoustic component of the airpuff than by the tactile component of that airpuff. The vibrotactile pulse used in the present study was a purely vibratory stimulus, with no detectable acoustic component. The vibrator was covered by the hand, and the vibration involved 2.5 cycles of a $50-\mathrm{Hz}$ stimulus, so the possibility of an acoustic stimulus near blink threshold was minimal. This conclusion is supported by the absence of blinks on vibration-alone trials.

(Manuscript received November 8, 1996; revision accepted for publication March 3, 1997.) 